\title{
O gênero Piper L. (Piperaceae) da Mata Atlântica da Microbacia do Sítio Cabuçu-Proguaru, Guarulhos, SP, Brasil
}

\author{
Karen Cristina Bardelli ${ }^{1}$, Mizué Kirizawa ${ }^{1,4}$ e Amélia Vera Guimarães de Sousa ${ }^{2,3}$
}

Recebido: 22.09.2006; aceito: 23.10.2008

\begin{abstract}
The genus Piper L. (Piperaceae) of microbasin of Sítio Cabuçu-Proguaru Atlantic Rain Forest of Guarulhos, SP, Brasil). The Sítio Cabuçu-Proguaru is adjacent to Cabuçu nucleus of Parque Estadual da Cantareira located at the municipality of Guarulhos, São Paulo, Brazil. It is covered mainly by secondary Atlantic Rain Forest. In this area, Piper is represented by five species: $P$. crassinervium Kunth, $P$. gaudichaudianum Kunth, $P$. mollicomum Kunth, $P$. regnellii Miq. and P. umbellatum L. Genera and species descriptions, key to the species, illustrations and comments on distribution, phenology and uses are provided.
\end{abstract}

Key words: Sítio Cabuçu-Proguaru, floristic, São Paulo State

RESUMO - (O gênero Piper L. (Piperaceae) da Mata Atlântica da microbacia do Sítio Cabuçu-Proguaru, Guarulhos, SP, Brasil). O Sitio Cabuçu-Proguaru é adjacente ao núcleo Cabuçu do Parque Estadual da Cantareira, localizado no município de Guarulhos, São Paulo, Brasil. A vegetação dominante é Mata Atlântica secundária. Nessa área, o gênero está representado por cinco espécies: $P$. crassinervium Kunth., $P$. gaudichaudianum Kunth, $P$. mollicomum Kunth, $P$. regnellii Miq. e $P$. umbellatum L. São apresentadas descrições do gênero e das espécies, chave de identificação, ilustrações e comentários sobre distribuição, fenologia e usos.

Palavras-chave: Estado de São Paulo, florística, Sítio Cabuçu-Proguaru

\section{Introdução}

O Sítio Cabuçu-Proguaru, com área de aproximadamente 60 ha, localiza-se ao sul do Parque Estadual da Cantareira, em Guarulhos, SP, distando aproximadamente $8 \mathrm{~km}$, em linha reta, da região central desse município. O relevo local é montanhoso, de serras alongadas, com altitude entre 750-1.215 m. A temperatura média anual da região é de $18,2{ }^{\circ} \mathrm{C}$, sendo fevereiro o mês mais quente, e julho, o mais frio. O período de chuvas vai de outubro a março, com média anual de $1.400 \mathrm{~mm}$. A vegetação enquadrase na floresta ombrófila densa (Mata Atlântica), perturbada por atividades antrópicas (Clauset \& Soares 1999). Segundo informações de moradores da região, no início do século XIX, parte da vegetação foi removida para cultivo, principalmente de canade-açúcar e chuchu, seguida de intensa retirada de madeira para alimentar as olarias, além do uso da área como pastagem. Na década de 1930, as olarias foram abandonadas, possibilitando a regeneração da vegetação.
Em 2003 teve início o Projeto "Diagnóstico ambiental para o manejo sustentável do Núcleo Cabuçu do Parque Estadual da Cantareira e áreas vizinhas do município de Guarulhos", com participação da Universidade Guarulhos e Prefeitura de Guarulhos, entre outras entidades (Oliveira 2005). O Sítio Cabuçu-Proguaru refere-se à área da microbacia Proguaru, sub-bacia Cabuçu, e que faz parte do entorno ou da zona de defesa do Núcleo Cabuçu, hoje oficializada como Área de Proteção Ambiental Cabuçu-Tanque Grande. A denominação Sítio Cabuçu é antiga, sendo um dos loteamentos do bairro do Cabuçu e que abriga o Proguaru (Centro Administrativo Progresso e Desenvolvimento de Guarulhos SA.), autarquia da Prefeitura de Guarulhos. Esta região, parcialmente afetada por atividades antrópicas, contém fragmentos florestais em recuperação, cuja flora é pouco conhecida, sendo ainda escassas as informações sobre uso das plantas pela comunidade. Sabe-se, no entanto, que uma das famílias representativas é Piperaceae.

1. Instituto de Botânica, Seção de Curadoria do Herbário, Caixa Postal 3005, 01061-970 São Paulo, SP, Brasil

2. Universidade Guarulhos, Praça Tereza Cristina 1, 07023-070 Guarulhos, SP, Brasil

3. Universidade Presbiteriana Mackenzie, Rua da Consolação 896, 01302-907 São Paulo, SP, Brasil

4. Autor para correspondência: mkirizawa@yahoo.com.br 
A família Piperaceae, com 10 gêneros e 1.4002.000 espécies no mundo, ocorre em toda a região tropical, freqüentemente em locais sombreados (Cronquist 1981). No Brasil, está representada pelos gêneros Ottonia Spreng., Peperomia Ruiz \& Pav., Piper L., Pothomorphe Miq. e Sarcorhachis Trel., totalizando 450 espécies. Piper. e Peperomia são os maiores gêneros, respectivamente com 265 e 166 espécies (Yuncker 1972, 1973, 1974). Atualmente, Pothomorphe esta incluído no gênero Piper (Tebbs 1990). Várias espécies de Piper apresentam potencial medicinal (Di Stasi et al. 1989, Pio-Correa 1974, Guimarães et al. 1978) e, inclusive, são fontes de alimentos para alguns grupos de morcegos frugívoros. (Mello 2002).

Este estudo morfo-taxonômico tem como objetivo conhecer, descrever e ilustrar as espécies de Piper L. ocorrentes no Sitio Cabuçu-Proguaru, bem como fornecer informações sobre hábitat, distribuição geográfica, fenologia e usos, contribuindo para o conhecimento, principalmente de plantas com potencial medicinal, para a conservação da flora da Mata Atlântica da região e para o desenvolvimento de futuras pesquisas.

\section{Material e métodos}

Para o desenvolvimento deste trabalho, procurouse, inicialmente, conhecer o fragmento de Mata Atlântica da microbacia do Proguaru - Sítio CabuçuProguaru - com área de aproximadamente 60 ha, localizada ao sul do Núcleo Cabuçu do Parque Estadual da Cantareira, no município de Guarulhos, SP, Brasil. Nessa região montanhosa e íngreme, existem muitas nascentes que formam diversos cursos d’água, como o córrego Pires e o rio Cabuçu de Cima, afluente do rio Tietê, que corre a oeste do Sítio Cabuçu-Proguaru; ele também abriga pequenos riachos. No período de 2004 a 2005, foram realizadas visitas periódicas à região da mata remanescente do Sítio para coleta das Piperaceae.

O material botânico foi herborizado conforme as técnicas constantes em Fidalgo \& Bononi (1984); uma parte desse material foi depositada no Herbário Prof. Dr. Albrecht August Oswald Tabor da Universidade Guarulhos (UnG) e a outra, no
Herbário Maria Eneyda P. Kauffmann Fidalgo (SP) do Instituto de Botânica.

Para análise morfo-taxonômica do gênero Piper, visando sua identificação e descrição das espécies, foram utilizados os trabalhos de Guimarães et al. (1978), Guimarães \& Valente (2001), Miquel (1852), Tebbs $(1989,1990,1993)$ e Yuncker $(1972,1973$, 1974) e/ou método de comparação com exsicatas depositadas no Herbário SP.

As descrições das espécies de Piper foram também complementadas com estudo do material coletado em outras regiões dos Estados de São Paulo e Rio de Janeiro. Informações adicionais, como nomes populares, distribuição, fenologia e usos, foram extraídos da literatura citada e/ ou das etiquetas de exsicatas analisadas.

\section{Resultados e Discussão}

Foram encontradas na mata do Sítio CabuçuProguaru cinco espécies do gênero Piper L. todas arbustivas, que crescem no interior do sub-bosque ou na orla de trilhas da floresta ombrófila densa secundária, que recobre os morros da microbacia Proguaru.

São apresentadas as descrições do gênero Piper e das espécies, além da chave para as espécies.

Piper L., Gen. Pl. ed. 1. 333. 1737.

Arbusto, subarbusto ou arvoreta, 1-10 m alt., ocasionalmente escandente. Caule comumente nodoso. Folhas alternas; lâmina com base freqüentemente assimétrica, glabra ou pilosa, glandulífera, às vezes rugosa ou bulada; pecíolo comumente vaginado-sulcado na base ou até o ápice, formando expansões aladas. Inflorescência em espiga, oposta às folhas. Flores densamente congestas ou laxas; bractéolas glabras ou mais comumente pilosas ou fimbriadas; estames 2-5; ovário glabro ou com tricomas, estigmas geralmente 3 , sésseis ou não. Fruto séssil, de forma variável, pericarpo pouco espessado.

O gênero é amplamente distribuído em regiões tropicais e temperadas de ambos os hemisférios (Ichaso et al. 1977, Guimarães \& Giordano 2004.). 
Chave para as espécies de Piper do Sítio Cabuçu-Proguaru

1. Espigas agrupadas em pseudo-umbelas P. umbellatum

1. Espigas isoladas, não agrupadas.

2. Lâmina foliar glabra na face adaxial ou pubescente sobre nervuras, não escabrosa; espiga retilínea ou levemente curva.

3. Espiga apiculada; pedúnculo 0,2-0,5 cm compr., pubescente; estames 4; estilete curto; lâmina ovada, ovado-elíptica a lanceolada P. crassinervium

3. Espiga não apiculada; pedúnculo 1,5-3,0 cm compr., glabro, estames 3; estigma séssil; lâmina ovado-arredondada ou cordiforme P. regnellii

2. Lâmina foliar escabrosa na face adaxial; espiga curvada.

4. Face abaxial escabriúscula a pubescente; nervuras com tricomas adpressos; drupa ca. 0,4 mm compr., oblongo-obovóide, ápice piloso P. gaudichaudianum

4. Face abaxial vilosa a pubérula; nervuras sem tricomas adpressos; drupa ca, 0,7 mm compr., obovóide, ápice glabro P. mollicomum

Piper crassinervium Kunth, Nov. Gen. \& Sp. 1: 48.1815

Nomes populares: pariparoba, jaguarandi.

Figuras 1-5

Arbusto 2-5 m alt. Ramos glabros. Folha com profilo em forma de capuz, caduco; lâmina 10,518,5 × 3-9 cm, ovada, ovado elíptica a lanceolada, ápice longamente acuminado, base subassimétrica, obtusa, ocasionalmente cuneada, margem inteira, não escabrosa; face adaxial glabra ou pubescente, abaxial glabra a pubescente, mais na base das nervuras maiores; nervação camptódroma, 4 nervuras secundárias de cada lado da nervura principal, saindo em ângulo agudo na metade inferior da lâmina, proeminentes em ambas as faces, mais na abaxial, nervuras menores com anastomoses nas proximidades da margem; pecíolo $0,5-2,5 \mathrm{~cm}$, glabro a glabrescente, canaliculado, levemente alado até cerca da metade de seu comprimento, evidente nas folhas jovens. Espigas isoladas, levemente curva, 4-7,5 cm, apiculada, retilínea na frutificação; pedúnculo 0,2$0,5 \mathrm{~cm}$, pubescente; bráctea triangular, arredondada, subpeltada, franjada no bordo; estames 4 , filete ca. 1 $\mathrm{mm}$, ovário $8 \mathrm{~mm}$, ovado, estilete ca. $6 \mathrm{~mm}$, estigmas quase do mesmo comprimento do estilete. Drupa ovóide, glabra.

Espécie reconhecida principalmente pelas folhas de base simétrica ou quase, nervuras secundárias conspícuas que partem em ângulo agudo na metade inferior da nervura mediana, espiga apiculada e pelo ovário, com estilete. Ocorre na Colômbia, no Equador e Peru; no Brasil, nos Estados das Regiões Norte,
Nordeste, Sudeste e Sul (Guimarães \& Giordano 2004). Desconhece-se o uso da espécie na medicina caseira; mas, há informações da presença de óleo essencial (Albiero et al. 2005). Os frutos de $P$. crassinervium constituem uma importante fonte de alimento para os morcegos (Guimarães et al. 2001). Geralmente floresce e frutifica no outono e inverno; no Sítio Cabuçu, foi coletada com flores em março e frutos em maio.

Material examinado: BRASIL. SÃo PAULO: Guarulhos, Sítio Cabuçu-Proguaru, 13-III-2005, K.C. Bardelli 3 (SP); idem, 11-V-2005, K.C. Bardelli 8 (SP).

Material adicional examinado: BRASIL. São PAULO: Araraquara, Jardim Botânico de Araraquara 10-III1998, M. Kato s.n. (SP358934).

Piper gaudichaudianum Kunth, Linnaea 13: 638. 1839.

Nomes populares: murta, pariparoba.

Figuras 6-10

Arbusto até $3 \mathrm{~m}$ alt., pubescente. Ramos com muitos tricomas retrorsos. Folha com profilo em capuz, caduco, visível apenas nas folhas jovens; lâmina 8-17 × 3-7 cm, largamente elíptica, ovadoelíptica a lanceolada, ápice acuminado a falcado, base assimétrica, aguda a obtusa, um lado 1-4 mm mais curto que o outro, em relação ao pecíolo, margem inteira, rugosa tardiamente, face adaxial fortemente escabrosa, face abaxial escabriúscula a pubescente, com numerosos tricomas adpressos nas nervuras; nervação camptódroma na base, acródroma no ápice, com 4-5 nervuras secundárias de cada 


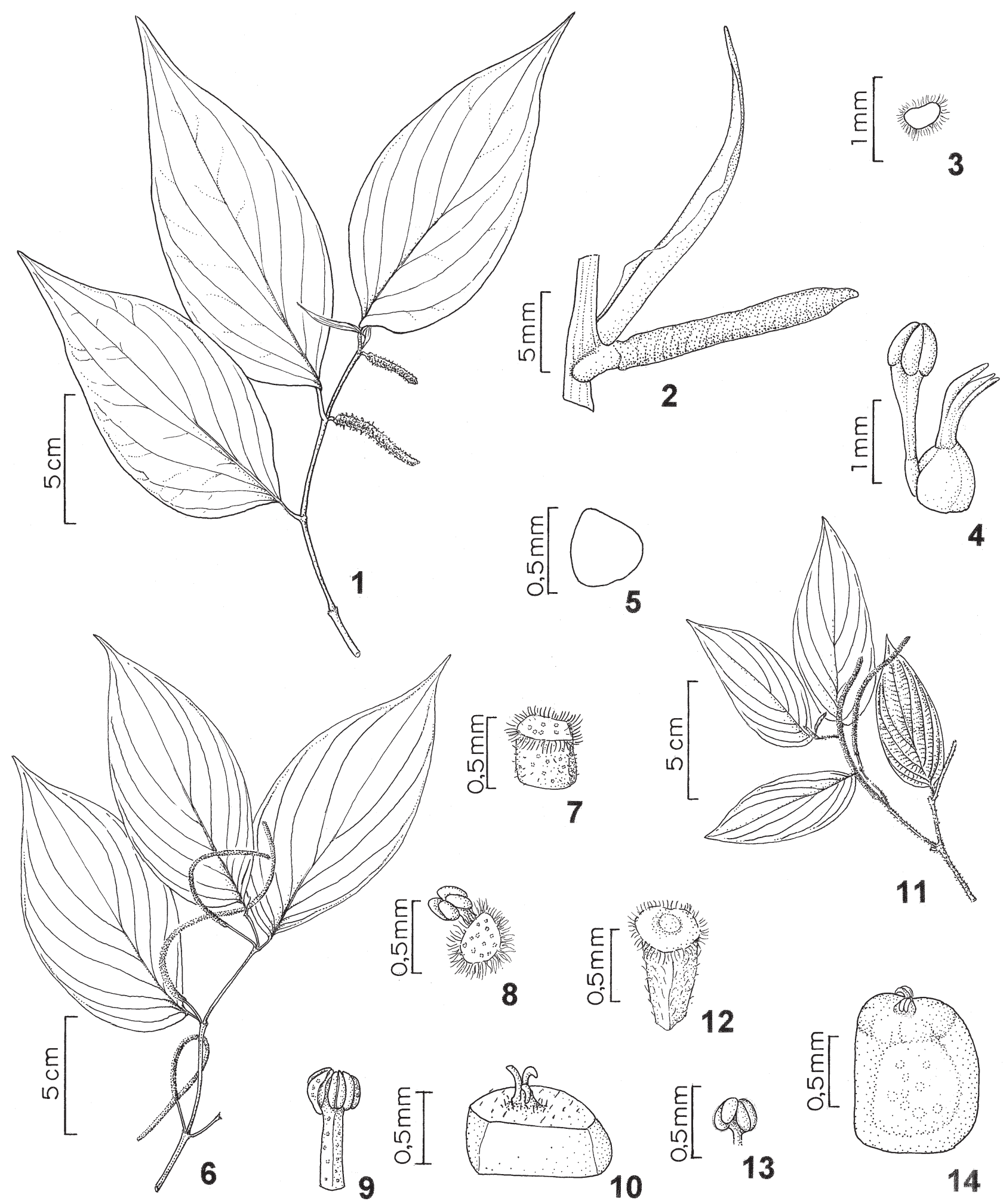

Figuras 1-5. P. crassinervium. 1. Ramo com espigas. 2. Detalhe do profilo e espiga jovem. 3. Bractéola. 4. Estame e ovário estiloso. 5. Semente. Figuras 6-10. P. gaudichaudianum. 6. Ramo com espigas. 7. Bractéola. 8. Bractéola e estame, em vista frontal. 9. Estame. 10. Drupa. Figuras 11-14. P. mollicomum. Ramo com espigas. 12. Bractéola. 13. Estame. 14. Drupa (1: Bardelli 8; 2-5: Bardelli 3; 6-10: Bardelli 6; 11-14: Bardelli 4). 
lado da nervura principal até a metade da lâmina, ascendentes, impressas na face adaxial, salientes na abaxial, nervuras terciárias abundantes; pecíolo 0,3-1,2 cm, pubescente, bainha pouco desenvolvida. Espiga isolada, não agrupada, 4-15 cm, curvada; pedúnculo 1-2 cm, densamente pubescente; bractéolas triangulares a arredondadas, subpeltadas, franjadas na margem; estames 4; estigmas sésseis. Drupa ca. 0,4 mm compr., oblongo-obovóide, comprimida lateralmente, ápice piloso, glândulas puntiformes nas faces laterais.

De distribuição geográfica ampla, $P$. gaudichaudianum ocorre na Argentina, no Paraguai e nas Regiões Nordeste, Sudeste e Sul do Brasil. Encontrada em clareiras e bordas de florestas, sendo uma das pioneiras mais comuns (Guimarães \& Valente 2001); ainda, segundo esses autores, estudos fitoquímicos indicaram a ocorrência de sitosterol e estigmasterol, produtos com atividades antiinflamatória e analgésica. Os frutos, fonte de alimento para morcegos, associados à rusticidade da espécie possibilitam seu aproveitamento em projetos de restauração de ambientes, ao proporcionar cobertura arbustiva em solos pobres. Floresce durante todo o ano e frutifica em janeiro, março, agosto e de outubro a dezembro (Guimarães \& Valente 2001); no Sítio Cabuçu, foi coletada com flores em novembro e frutos em setembro.

Material examinado: BRASIL. SÃo PAULO: Guarulhos, Sítio Cabuçu-Proguaru, 15-XI-2004, K.C. Bardelli 5 (SP); idem, 18-IX-2004, K C. Bardelli 6 (SP); 18-IX2004, K.C. Bardelli 7 (SP).

Material adicional examinado: BRASIL. SÃo PAUlo: Caieiras, 8-XII-1936, M. Kuhlmann s.n. (SP37064); São Paulo, Parque do Estado, 11-XI-1960, J.R. Mattos \& N.F. Mattos 8437 (SP); São Paulo, Serra da Cantareira, 16-X-1992, J.A. Pastore \& L. Marino 439 (SP).

Piper mollicomum Kunth, Linnaea 13: 648. 1839.

Nomes populares: pariparoba, jaguarandi, jaborandi ou jaborandi-manso.

Figuras 11-14

Arbusto até $3 \mathrm{~m}$ alt. Ramos pubescentes. Folha com profilo formando capuz, caduco, visível apenas em folhas jovens; lâmina 9-15 × 2,3-6,5 cm, ovadoelíptica, bulada quando adulta, ápice longamente acuminado, base obtusa, assimétrica, um lado até
$5 \mathrm{~mm}$ mais curto que outro, em relação ao pecíolo, margem inteira, face adaxial escabrosa, abaxial vilosa a pubérula, mais densa nas nervuras, sem pêlos adpressos; nervação camptódromo-acródroma, 4-6 nervuras secundárias de cada lado da nervura principal, originadas na metade inferior da lâmina, nervuras terciárias transversais com anastomoses na região do bordo; pecíolo 0,5-1(-1,8) cm, pubescente, bainha evidente na base. Espiga isolada, não agrupada, 7-10 cm, curvada; pedúnculo 0,5-2 cm, pubérulo; bractéolas triangulares subpeltadas, densamente franjadas na margem; estames 4; estigmas sésseis. Drupa ca. 0,7 mm compr, obovóide, ápice glabro.

Piper mollicomum distingue-se das outras espécies estudadas, ao apresentar lâminas foliares densamente vilosas a pubérulas na face abaxial e espigas recurvadas. Ocorre no Brasil, nos Estados de Ceará, Paraíba, Pernambuco, Minas Gerais, Espírito Santo, Rio de Janeiro, São Paulo, Paraná e Santa Catarina, Goiás e Mato Grosso, sendo bastante freqüente em matas úmidas e restingas, entre 200-600 m.s.m., beira de estradas, locais ensolarados ou semisombrios (Guimarães \& Giordano 2004). A população utiliza os frutos para tratar de problemas estomacais, doenças venéreas, e as raízes como mastigatórios para anestesiar as dores de dentes (Peckolt \& Peckolt 1888, Guimarães \& Giordano 2004). As folhas de $P$. mollicomum contêm óleos essenciais que demonstram moderada ação antibacteriana (Guimarães \& Valente 2001). Encontrada florescendo em outubro e frutificando em novembro; no Sítio Cabuçu, coletada com frutos em outubro.

Material examinado: BRASIL. SÃo PAULO: Guarulhos, Sítio Cabuçu-Proguaru, 31-X-2004, K.C. Bardelli 4 (SP).

Material adicional examinado: BRASIL, RIO DE JANEIRO: Rio de Janeiro, Silva Jardim, 19-XI-1982, J.R. Pirani et al. 142 (SP); São Paulo: São Paulo, Parque Estadual das Fontes do Ipiranga, 28-X-1980, F. Barros \& S.L. Jung 555 (SP).

Piper regnellii (Miq.) C.DC. in DC. Prodr. 16(1): 307. 1869.

Figuras 15-19

Arbusto 1-4 m alt. Ramos glabros, estriadosulcados, com glândulas. Folhas longo- pecioladas, profilo caduco; lâmina ca. $5 \times 7-17 \mathrm{~cm}$, ovadoarredondada ou cordiforme, ápice agudo a 


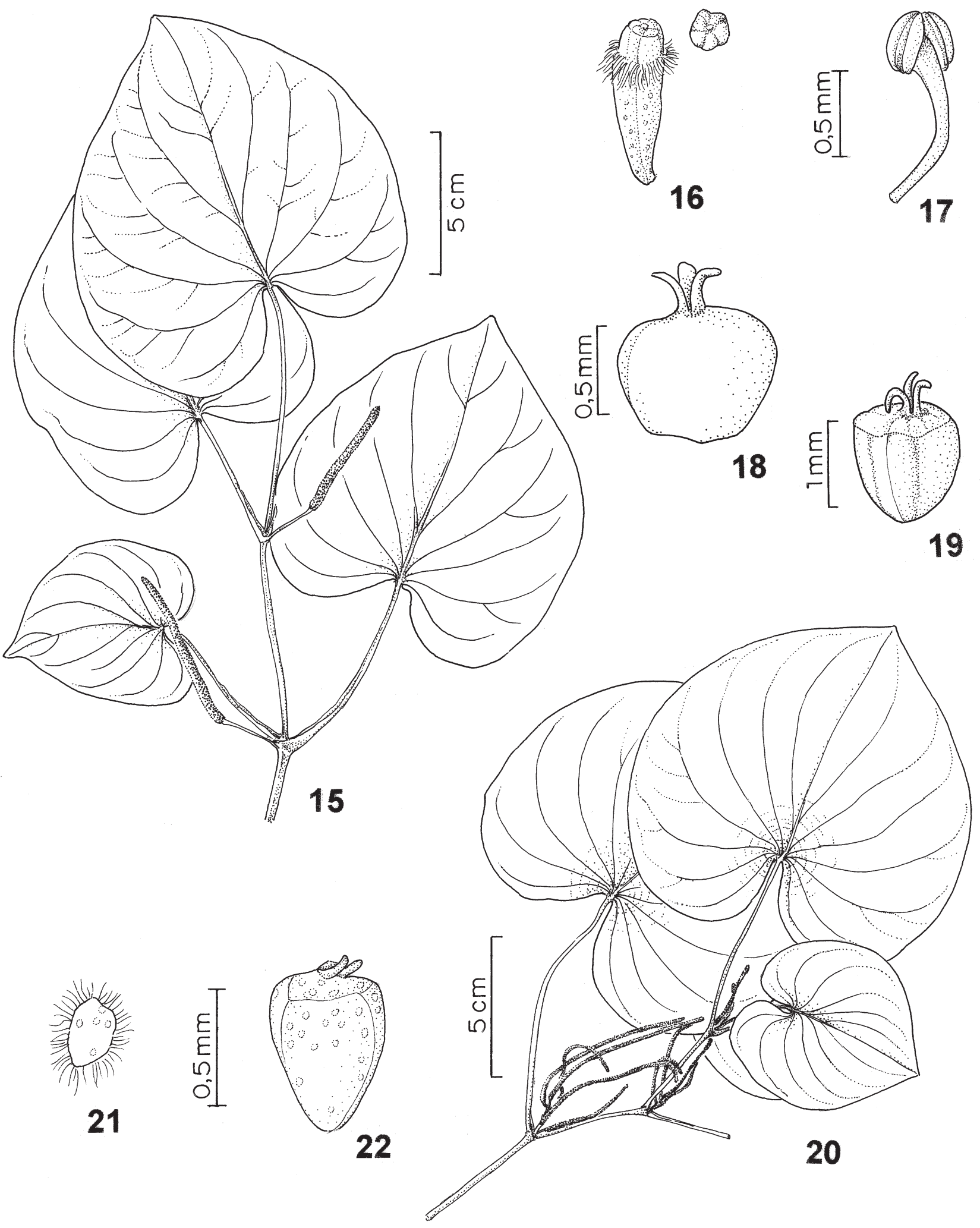

Figuras 15-19. P. regnellii. 15. Ramo com espigas. 16. Bractéola. 17. Estame. 18. Ovário. 19. Drupa. Figuras 20-22. P. umbellatum. 20. Ramo com pseudo-umbelas. 21. Bractéola. 22. Drupa (15-19: Bardelli 2; 20-22: Bardelli 1). 
abruptamente acuminado, base cordada ou com sinus obtuso, margem inteira, lisa, numerosas glândulas puntiformes, faces adaxial e abaxial glabras, exceto sobre nervuras pubescentes; venação acródromobroquidódroma, 9 nervuras palmatinérveas, de cada lado da nervura mediana, a 1-4,5 cm da base, saem 2-5 nervuras secundárias, as duas primeiras mais robustas; pecíolo 3,5-12 cm, bainha até a metade ou um pouco além, canaliculada, glabro a glabrescente. Espiga isolada, não agrupada, 4,5-11 cm, não apiculada, retilínea ou levemente curva; pedúnculo $1,5-3 \mathrm{~cm}$, glabro, estriado, glândulas puntiformes castanhoavermelhadas; bractéola orbicular, triangular a poligonal, convexa, ápice levemente deprimido, franjas subapicais; estames 3; estigmas sésseis, recurvados. Drupa obovóide ou obpiramidal-triangular, glabra.

Piper regnelli distingue-se vegetativamente das outras espécies de Piper analisadas, pela forma e venação da lâmina foliar, pecíolo com bainha até a metade do seu comprimento; de $P$. umbellatum difere principalmente em apresentar espiga isolada, não organizada em pseudo-umbela. Em folhas jovens de P. regnellii, Silva \& Machado (1999) registraram a ocorrência de glândulas peroladas e saculiformes na epiderme, contendo lipídios, proteínas e polissacarídeos. Espécie popularmente utilizada no tratamento da dor, afecções febris e/ou reumáticas, apresenta atividade analgésica positiva (Di Stasi et al. 1989). Ocorre no Brasil e na Argentina, entre 400-1.000 metros de altitude; cresce em regiões úmidas, parcialmente sombreadas, e em florestas galeria (Tebbs 1990). No Estado de São Paulo, encontrada florescendo de maio a novembro (Yuncker 1972); na mata do Sítio Cabuçu, foi coletada com flores em novembro.

Material examinado: BRASIL. São PAULO: Guarulhos, Sítio Cabuçu-Proguaru, 15-XI-2004, K.C. Bardelli 2 (SP).

Material adicional examinado: BRASIL. São PAULO: Piraju, 15-V-1996, A. Rapini et al. 150 (SP); São Paulo, Butantan, VI-1920, F.C. Hoehne s.n. (SP 235).

Piper umbellatum L, Sp. pl. 1: 30.1753 $\equiv$ Pothomorphe umbellata (L.) Miq., Comm. Phytogr.: 36. 1840.

Nomes populares: pariparoba, malvavisco, capeba, lençol-de-santa-bárbara, catajé.

Figuras 20-22

Arbusto 1-3 m. Ramos estriados, pubescentes. Folhas longamente pecioladas; lâmina 7-23 ×
7,8-33,5 cm, densamente pontuada de glândulas, ovado-arredondada a reniforme, ápice abruptamente acuminado, base cordada ou com sinus $2,5-5 \mathrm{~cm}$ de profundidade, margem inteira, face adaxial glabra a glabrescente, abaxial pubescente, particularmente nas nervuras; nervação acródromo-broquidódroma, em geral 12 nervuras ascendentes, destas 3-6 partem de cada lado da nervura mediana a 1-2 cm da base da lâmina, nervuras internervurais basais em semicírculos e anastomoses de nervuras de menor porte na região do bordo; pecíolo $4-15 \mathrm{~cm}$, vaginado até o terço inferior, estriado, pubescente ou quase estrigoso, numerosas glândulas puntiformes. Espigas agrupadas, 4-10 cm, pedúnculos 0,2-0,4 cm, dispostas em vários níveis sobre pedúnculo comum de 0,5-2 cm, formando pseudo-umbelas; bractéolas triangulares, arredondadas a subpeltadas, glandulosas, franjas marginais, alvas e longas; estames 2; estigmas sésseis. Drupa obpiramidal-trigonal, glândulas ovais, amarelas.

Morfologicamente, $P$. umbellatum é facilmente reconhecida pelas espigas agrupadas, parecendo umbelas (Guimarães et al. 1978), forma das folhas e dos frutos, pontuados de glândulas puntiformes, amareladas, com óleo essencial (Martins et al. 1998). Ocorre na América Central, Antilhas e América do Sul; no Brasil, em Estados da Regiões Norte, Nordeste, Sudeste e parte da Sul (Yuncker 1973, Guimarães et al. 1978, Tebbs 1993). Piper umbellatum é utilizada na medicina caseira pelas populações de vários países. No Brasil, toda a planta, principalmente as folhas, é utilizada sob a forma de chá, suco ou emplasto, como antiblenorrágica, vermífuga e no combate das inflamações internas (tosse, bronquite) e externas, em machucados ou queimaduras (Peckolt \& Peckolt 1888, Pio-Correa 1974, Lorenzi \& Matos 2002). Suas folhas e raízes são também empregadas sob a forma de chá, em doenças do fígado, baço e rim, contra inchaços e inflamações das pernas (Guimarães et al. 1978, Di Stasi et al. 1989); elas teriam, também, propriedades antiescorbúticas, diuréticas e vermífugas (Pio-Correa 1974). Estudo farmacológico realizado com essa planta confirmou sua atividade antimalárica ou antioxidante, enquanto a pesquisa fitoquímica possibilitou a identificação do composto "nerolidylcatecholo" (Lorenzi \& Matos 2002). Piper umbellatum pode ser aproveitada como planta ornamental (Lorenzi \& Souza 1999). Floresce em várias épocas do ano (Yuncker 1973); no sítio Cabuçu-Proguaru foi coletada em dezembro. 
Material examinado: BRASIL. SÃo PAULO: Guarulhos, Sítio Cabuçu-Proguaru, 18-III-2005, K.C. Bardelli 1 (SP).

Material adicional examinado: BRASIL. São PAULO: Cubatão, Serra do Morrão, 5-VI-1999, M. Kirizawa \& S.A.C. Chiea 2339 (SP); Sete Barras, 1-XII-1977, S.M.C. Dietrich s.n. (SP154659).

O estudo, apesar de pontual, pode contribuir para o conhecimento da flora local, em especial da família Piperaceae representada pelo gênero Piper, uma vez que praticamente não se têm informações sobre espécies fanerogâmicas no Núcleo Cabuçu e, muito menos na área do entorno. O mesmo não acontece nas unidades de conservação localizadas na Serra do Mar, como a Ilha do Cardoso (Barros et al. 1991), Juréia (Mamede et al. 2001) e Reserva Biológica do Alto da Serra de Paranapiacaba (Kirizawa et al. 2003), cuja flora é conhecida. Considerando as Piperaceae dessas reservas, há espécies de Piper do Sítio Cabuçu-Proguaru, como a $P$. regnellii, $P$. umbellatum, $P$. crassinervium e $P$. mollicomum, que não ocorrem na Reserva de Paranapiacaba, representada por oito espécies de Piper; de comum apenas $P$. gaudichaudianum. Mas, esta última, além de $P$. regnellii e $P$. umbellatum, entre 11 espécies citadas, foi encontrada na Ilha do Cardoso. $\mathrm{Na}$ Juréia, das 12 espécies coletadas nesta Reserva, apenas $P$. gaudichaudianum e $P$. mollicomum são comuns com as do Sítio Cabuçu-Proguaru. Portanto, a representatividade de Piper no Sítio corresponde quase à metade das três unidades de conservação, muito maiores em termos de área.

Na Ilha do Cardoso, na região de Ipanema, $P$. umbellatum é cultivada pelos caiçaras que utilizam suas raízes e folhas para tratar de dores físicas, sob a forma de cataplasma ou chá (Guimarães 1999). Não muito longe da área do Sítio Cabuçu-Proguaru, há comunidades rurais que, provavelmente, podem ter algum conhecimento popular do uso de algumas plantas nativas da Mata Atlântica, talvez de algumas Piperaceae, como P. umbellatum ou de outras espécies do mesmo táxon ocorrentes na região. Para averiguar essa informação há necessidade de pesquisas etnobotânicas; e, para uso adequado de plantas com potencial medicinal, de estudos farmacológicos, bioquímicos, entre outros; os agronômicas ajudariam na preservação de matrizes, evitando o extrativismo, e da diversidade da Mata Atlântica remanescente.

\section{Agradecimentos}

As autoras agradecem à Pesquisadora Dra. Elsie Franklin Guimarães, do Instituto de Pesquisas do Jardim Botânico do Rio de Janeiro, pela leitura critica do trabalho; à desenhista Maria Cecília Tomasi, do Instituto de Botânica, pela cobertura à nanquim das ilustrações e arte final.

\section{Literatura citada}

Albiero, A.L.M., Paoli, A.A.S., Souza, L.A. \& Mourão, K.S.M. 2005. Morfoanatomia dos órgãos vegetativos de Piper crassinervium H.B. \& K. (Piperaceae). Acta Botanica Brasilica 19: 305-312.

Barros, F., Melo, M.M.R.F., Chiea, S.A.C., Kirizawa, M., Wanderley, M.G.L. \& Jung-Mendaçolli, S.L. 1991. Caracterização geral da vegetação e listagem das espécies ocorrentes. In: M.M.R.F. Melo, F. Barros, M.G.L.Wanderley, M. Kirizawa, S.L. Jung-Mendaçolli \& S.A.C. Chiea (eds.) Flora Fanerogâmica da Ilha do Cardoso, v. 1. Instituto de Botânica, São Paulo.

Clauset, L.R. \& Soares, D. 1999. Paisagem Paulista: áreas protegidas. Empresa das Artes, São Paulo.

Cronquist, A. 1981. An integrated system of classification of flowering plants. University Press, New York.

Di Stasi, L.C., Santos, E.M.G., Santos, C.M. \& Hiruma, C.A. 1989. Plantas medicinais na Amazônia. Editora Universidade Estadual Paulista Júlio de Mesquita Filho, São Paulo.

Fidalgo, O. \& Bononi, V.L.R. (coords.). 1984. Técnicas de coleta, preservação e herborização de material botânico. Manual $n^{\circ}$ 4. Instituto de Botânica, São Paulo.

Guimarães, E.F. 1999. Flora Fanerogâmica da Ilha do Cardoso (São Paulo, Brasil). Piperaceae. In: M.M.R.F Melo, F. Barros, S.A.C. Chiea, M. Kirizawa, S.L Jung-Mendaçolli \& M.G.L. Wanderley (eds.). Flora Fanerogâmica da Ilha do Cardoso 6: 15-43.

Guimarães, E.F. \& Giordano, L.C.S. 2004. Piperaceae do nordeste brasileiro I: Estado do Ceará. Rodriguésia 55: 21-46.

Guimarães, E.F. \& Valente, M.C. 2001. Piperaceae Piper. In: R. Reitz (ed.). Flora Ilustrada Catarinense, Herbário Barbosa Rodrigues, Itajaí.

Guimarães, E.F., Ichaso, C.L. \& Costa, C.G. 1978. Piperaceae. 1. Ottonia, 2. Sarcorhachis, 3. Pothomorphe. In: R. Reitz (ed.). Flora Ilustrada Catarinense, Herbário Barbosa Rodrigues, Itajaí.

Ichaso, C.L.F., Costa, C.G. \& Guimarães, E.F. 1977. Piperaceae do município do Rio de Janeiro. Arquivos do Jardim Botânico do Rio de Janeiro 20: 145-187.

Kirizawa, M., Sugiyama, M., Lopes, E.A. \& Custodio Filho, A. 2003. Flora Fanerogâmica da Reserva 
Biológica do Alto da Serra de Paranapiacaba, Santo André, SP, Brasil. www.ibot.sp.gov.br/Pesquisa/ Paranapiacaba (acesso em 08.12.2004).

Lorenzi, H. \& Sousa, H.M. 1999. Plantas ornamentais do Brasil: arbustivas, herbáceas e trepadeiras. Instituto Plantarum de Estudos da Flora, Nova Odessa.

Lorenzi, H. \& Matos, F.J.A. 2002. Plantas medicinais no Brasil: nativas e exóticas. Instituto Plantarum de Estudos da Flora Ltda., Nova Odessa.

Mamede, M.C.H., Cordeiro, I. \& Rossi, L. 2001. Flora vascular da Serra da Juréia,município de Iguape, São Paulo, Brasil. Boletim do Instituto de Botânica 15: 63-124.

Martins, A.P., Salgueiro, L., Vita, R., Tomi, F., Casanovoa, J., Proença-da-Cunha, A. \& Adzet, T. 1998. Essencial oils from four Piper species. Phytochemistry 49: 2019-2023.

Mello, M.A.R. 2002. Morcegos gostam de pimentas Ciência Hoje 32: 74-76.

Miquel, F.A.W. 1852. Chloranthaceae et Piperaceae. In: C.F.P. Martius \& A.G. Eichler (eds.). Flora brasiliensis, Lipsiae, Frid. Fleischer, v. 4, pars 1, pp. 1-76.

Oliveira, A.M.S. (coord.) 2005. Diagnóstico ambiental para o manejo sustentável do Núcleo Cabuçu do Parque Estadual da Cantareira e áreas vizinhas do município de Guarulhos. Projeto Cabuçu UnG/FAPESP, Relatório Final. Universidade Guarulhos, Guarulhos

Peckolt, T. \& Peckolt, G. 1888. História das plantas medicinais e úteis do Brasil. Lemmert, Rio de Janeiro.
Pio-Correa, M. 1974. Dicionário de plantas úteis do Brasil e das exóticas cultivadas. v. 5. Ministério da Agricultura, Instituto Brasileiro de Desenvolvimento Florestal, Rio de Janeiro.

Silva, E.M.J. \& Machado, S.R. 1999. Estrutura e desenvolvimento dos tricomas secretores em folhas de Piper regnelli (Miq.) C.DC. var. regnelli (Piperaceae). Revistra Brasileira de Botânica 22: 117-124.

Tebbs, M.C. 1989. Revision of Piper (Piperaceae) in the New World 1. Review of characters and taxonomy of Piper Section Macrostachys. Bulletin of British Museum (Natural History) Botany 19: 117-158.

Tebbs, M.C. 1990. Revision of Piper (Piperaceae) in the New World 2. The taxonomy of Piper Sction Churumayu. Bulletin of British Museum (Natural History) Botany 20: 193-236.

Tebbs, M.C. 1993. Revision of Piper (Piperaceae) in the New World 3. The taxonomy of Piper Sections Lepianthes and Radula. Bulletin of the Natural History Museum (Botany) 23: 1-50.

Yuncker, T.G. 1972. The Piperaceae of Brazil. Hoehnea 2: 19-366.

Yuncker,T.G. 1973. The Piperaceae of Brazil. II. Pipergroup V; Ottonia; Pothomorphe; Sarcorhachis. Hoehnea 3: 29-284.

Yuncker,T.G. 1974. The Piperaceae of Brazil. III. Peperomia; taxa of uncertain status. Hoehnea 4: 71413. 